\section{Transport processes in animals}

Transport of lons and Water in Animals. Edited by G. L. Gupta, J. L. Oschman, R. B. Moreton and B. J. Wall. Pp. 817. (Academic: London, New York and San Francisco, 1978.) $£ 32$.

THE thirty chapters in this book, each of different authorship and originating from several different countries, have been assembled as a tribute to Professor J. A. Ramsay who retired from the Chair of Comparative Physiology at Cambridge in 1976. Professor Ramsay has won great renown and respect as a pioneer in the development of microtechniques and in the application of these to the study of transepithelial transport, especially in insects. However, the contributions to this volume range widely over the animal kingdom, from amoebae to mammals and, as Professor Ussing observes in his prolegomena, the book could be regarded as a 'short-cut' to the ideas developed about transport processes from work on a wide variety of experimental preparations.

Among the contributions primarily devoted to techniques, there is an admirable review of the use of X-ray spectrometry as an adjunct to electron microscopy by Gupta, Hall and Moreton. This technique, though calling for great care in the preparation of specimens, offers the remarkable capability of revealing concentration gradients within single cells.

Renal physiology is represented by succint yet balanced surveys of micropuncture and the perfusion of isolated tubular segments by $G$. Giebisch and W. H. Dantzler respectively. The vertebrate gall-bladder, which has proved so useful in the study of isotonic transfer, is discussed by $T$. Zeuthen and the fish gill, noted for its so-called "chloride cells", is the subject of a chapter by W. T. W. Potts and also receives some attention from $\mathrm{L}$. B. Kirschner in the wider context of saltexcretion by marine vertebrates.

A rather general and mildly provocative evaluation of current models designed to elucidate the mechanism of salt/water coupling comes from the pen of A. E. Hill and includes a consideration of the possible involvement of electroa-osmosis. Also of a rather general nature is the excellent account by $\mathrm{N}$. J. Abbott and J. Treherne of homoeostatic processes in the brain.

Intercellular junctions, predictably, figure prominently in many parts of the text but gap junctions attract a very detailed treatment in a beautifully illustrated and thought-provoking article by W. J. Larsen, which suggests for them a special significance in hormone-responsive tissues. Like intercellular junctions potential measurements are frequently mentioned since many authors base their arguments very heavily upon them and the clear message comes through that electrophysiology is no longer the speciality of workers on excitable tissues.

Topics which are perhaps less central to the main theme of the book but which provide fascinating reading, are transpiration in arthropods, which is dealt with by E. B. Edney, and the uptake of water-vapour by insects and other small creatures, which is graphi-

\section{Southern African biogeography and ecology}

Biogeography and Ecology of Southern Africa. Vols 1 and 2. Edited by M. J. A. Werger. Pp. 1-660 and 661-1439. (Junk: The Hague, 1978.) DGu. 365.

To say that any attempt at condensing the biogeography and ecology of southern Africa into two volumes is a difficult task is a gross understatement. This being so, M. J. A. Werger has completed a courageous undertaking in editing a collection of review papers broadly dealing with this subject. He tackled the problem by devoting an introductory section to the physical and geological environment of the region, together with the history of its biota. There follows a series of eight chapters dealing with geographical subdivisions of southern Africa, and then one chapter on primary production, followed by a series in which animal classes are treated individually. Several rather special groups are dealt with separately, such as freshwater organisms, marine habitats and the vegetation of heavy metal contaminated soils. Finally, a chapter is devoted to the conservation of southern African ecosystems.

The idea of a physical and historical introduction is a sound one. The time element is given emphasis at a variety of scales. For example, an extensive account of the late Cretaceous and Tertiary vegetation history is provided by Axelrod and Raven, who draw upon a fund of recent work in plate tectonics to produce the first major synthesis on this subject for 25 years. For the general ecologist this may rate as the high point of the book.

Van Zinderen Bakker continues with a sadly brief account of Quaternary vegetation changes. Generalisations are made concerning the vegetation zones of "a glacial maximum" and "an interglacial", but no indication is given cally described by J. Noble-Nesbitt. In addition there are more specialised articles on subjects which include the rectum and salivary glands of the cockroach, the excretory organs of larvae and the antennal gland of the crayfish.

For the generality of physiologists it may be fairly claimed that this book offers something for everyone and for most of them everything in it will be something worth reading. Unfortunately its cost will make it a luxury.

R. V. Coxon

R. V. Coxon is Reader in Human Physiology at the University of Oxford, UK.

concerning the number of sites for which pollen data is available and their geographical locations. Neither is any pollen diagram presented. More detail should have been given to this part of southern Africa's history, the understanding of which is vital for any assessment of the present or future states of vegetation in the area.

Short term climatic variations are dealt with in a paper by Tyson, who describes 10- and 20-yr rainfall cycles, based on meteorological records and dendrochronology. Such data is of impartance in understanding the role of climate and land use in the recent desertification of areas previously covered with grass.

The remainder of the first volume concentrates upon the phytogeography of this varied area. Each part of the region has its own interest, from the exceptional floristic richness of the cape region (some $100 \mathrm{~m}^{2}$ quadrats may contain more than 120 angiosperm species) to the open communities of the Namib desert. These accounts are basically descriptive, but attempts are made to relate the communities described to the major environmental factors controlling their composition and distribution. The impact of grazing and fire is discussed, but little information seems to be available concerning secondary succession in the area. The arrangement of the animal data in a taxonomic rather than biogeographical form is unfortunate in that one loses sight of the animal-plant relationships as a consequence. It was, however, probably unavoidable, as different authors are responsible for each animal group.

The two volumes form a valuable body of reference on which more data will accrete. As with preceding volumes in this series, their appeal is mainly limited to those with research interests in the geographical area concerned.

Peter D. Moore

Peter D. Moore is Senior Lecturer in Plant Sciences at King's College, University of London, UK. 